\title{
Mechanical test of granite with multiple water-thermal cycles
}

\author{
Li Yu* (D, Hai-Wang Peng, Yu Zhang and Guo-wei Li
}

\author{
${ }^{*}$ Correspondence: \\ 964630415@qq.com \\ College of Civil Engineering \\ and Architecture, Hebei \\ University, Baoding 071002, \\ China
}

\begin{abstract}
To study the influence of thermal shock caused by water-cooling on the physical and mechanical properties of high-temperature granite, granite was subjected to an increasing number of high-temperature $\left(300^{\circ} \mathrm{C}\right)$ water-cooling and thermal shock treatment cycles, and static mechanical experiments were carried out on the treated granite. The results support the following conclusions: (1) thermal shock causes an increase in the number and size of the pores and cracks within the granite; thus, its volume expands, density decreases, water absorption rate increases, and P-wave velocity decreases. (2) With an increase in the number of thermal shocks, both the compressive strength and tensile strength of the granite decrease, and there is a linear relationship between the compressive strength and tensile strength. (3) With an increase in the number of thermal shocks, the plasticity of the granite increases and its resistance to deformation weakens, which is manifested as a decrease in both the compressive modulus and tensile modulus of the granite. After 15 cycles of thermal shock, the compressive elastic modulus and tensile modulus of the granite decreased by $25.18 \%$ and $46.76 \%$, respectively. (4) The $m$ and $s$ values of the damaged granite were calculated based on the Hoek-Brown empirical criterion, and it was found that both of these parameters decrease with the increase in the number of thermal shocks. The calculation results can provide a reference for engineering rock mass failure.
\end{abstract}

Keywords: Granite, Thermal shock, Uniaxial compression, Brazilian splitting, Mechanical properties

\section{Introduction}

Geothermal energy is a type of clean energy, mainly produced from high-temperature granite. In recent years, with the exploration and development of geothermal energy (Chen et al. 2019; Zhang et al. 2019a), considering the stability of surrounding rocks in deep drilling has become one of the hot issues in rock engineering research (Que et al. 2019). In the exploitation of geothermal energy, the key engineering problems lie in high-temperature drilling, wellbore surrounding rock stability, reservoir fracturing stimulation and stable thermal energy acquisition. To solve these key issues, it is necessary to consider the influence of cooling and thermal shock due to liquid circulation on the physical and mechanical behavior of high-temperature rocks.

At present, domestic and foreign scholars have carried out a considerable amount of research on issues related to the rock mechanics and exploitation of high-temperature

(c) The Author(s) 2021. This article is licensed under a Creative Commons Attribution 4.0 International License, which permits use, sharing, adaptation, distribution and reproduction in any medium or format, as long as you give appropriate credit to the original author(s) and the source, provide a link to the Creative Commons licence, and indicate if changes were made. The images or other third party material in this article are included in the article's Creative Commons licence, unless indicated otherwise in a credit line to the material. If material is not included in the article's Creative Commons licence and your intended use is not permitted by statutory regulation or exceeds the permitted use, you will need to obtain permission directly from the copyright holder. To view a copy of this licence, visit http://creativecommons. org/licenses/by/4.0/. 
rocks and complex geological environments (Rao et al. 1992; Yang et al. 2017; Li et al. 2018). Dai et al. (2018) analyzed the influence degree of different cooling methods, namely, natural cooling, sprinkler cooling and water impaction cooling, on the damage of granite after microwave irradiation by studying the temperature field changes and strength performance of the granite with thermal imaging tests and uniaxial compression tests. Zhang et al. (2019a, b) and Que et al. (2020) used acoustic emission and thermal infrared technology to monitor the changes in acoustic emission and infrared radiation of granite in the process of fracturing under uniaxial compression. The analytical expressions of rock damage variables based on acoustic emission and infrared radiation were established, and according to their complementarity in different stages, a piecewise curve damage model was established to analyze the characteristics of rock damage evolution under uniaxial compression. Ren et al. (2017) present a dual-horizon peridynamics formulation which allows for simulations with dual-horizon with minimal spurious wave reflection, and analyze the crack pattern of random point distribution and the multiple materials issue in peridynamics. Wang et al. (2019a, b) established a calculation model of the rock thermal rupture threshold based on the plane stress theory of elasticity. Yu et al. $(2019,2020)$ treated granite with thermal-hydraulic cycles at different temperatures, and uniaxial compression tests were used to analyze the variation in mechanical properties such as peak strength, peak strain and elastic modulus. Luo et al. (2020) took granite as the research object and conducted physical property tests and uniaxial compression tests on rock samples after natural cooling from high temperatures. The results show that both the peak strength and elastic modulus of the samples decrease. Que et al. (2020) studied the compressive strength, shear strength and tensile strength of granite thermal damage from Gonghe Basin, Qinghai Province, as well as the natural cooling and crack formation of granite specimens at high temperature by using a macroscopic mechanical test method combined with microscopic CT scanning Faoro et al. (2013). In order to better understand the complex coupling relationship between circulating fluid and fracture damage development, conducted the permeability tests on Etna basalt and Westerly granite samples loaded by periodic deviator stress, and measured the permeability and water volume content during the entire loading process. It is found that the permeability will decrease under low pressure differential stress, and increase under medium pressure differential stress until it reaches a stable value at failure. Jin et al. (2019) carried out two different types of thermal cycling treatments on granite samples (slow heating followed by slow cooling or rapid cooling). The changes in the physical and mechanical properties of the granite after various thermal cycling treatments were analyzed comparatively. Li et al. (2019) performed uniaxial compression tests on granite after different periodic high-temperature cooling treatments between $20{ }^{\circ} \mathrm{C}$ and $650{ }^{\circ} \mathrm{C}$, revealing the influence of thermal cycles on the crack damage development, strength decrease and failure mode of the granite. Xu et al. (2019) carried out a series of thermal cycling experiments on granite specimens at five temperatures to study the effect of thermal cycling on the mechanical properties of the granite Shu et al. (2019). The Hopkinson pressure bar (SHPB) splitting test system was used to perform cyclic impact loading test on the heat-treated rock. The correlation between energy dissipation, energy dissipation rate, number of impacts, cumulative absorbed energy per volume, failure mode and temperature is analyzed. Zhao et al. (2020) carried out cyclic 
temperature and loading tests to analyze the response of stress-strain characteristics of the granite samples to changes in temperature and cyclic load upper limit, while the number of temperature and loading cycles was comprehensively analyzed. Wang et al. (2020) used a scanning electron microscope equipped with a loading system to observe the fatigue crack behavior of Beishan granite after heat treatment at $50-600{ }^{\circ} \mathrm{C}$ in situ, and recorded the continuous cracking process under cyclic loading. The results show that the heat treatment caused the generation of thermal cracks and weakened the grain boundary strength of mineral particles, leading to different crack behaviors under cyclic loading. With the increase of temperature, the crack mode gradually changed from the forward propagation of new cracks to the continuous growth of the original cracks.

At present, the study on the thermal damage of granite mainly focuses on the influence of different cooling methods on its mechanical behavior at high temperatures. However, there are few studies on the physical and mechanical behavior of high-temperature granite after undergoing multiple thermal shocks. Therefore, the granite studied in this paper was subjected to high-temperature action at $300{ }^{\circ} \mathrm{C}$, and different numbers of high-temperature water-cooling and thermal shock treatments were conducted to study the changes in the physical and mechanical properties of the granite.

\section{Test overview}

\section{Granite specimen preparation}

The granite samples in this test come from the Shandong mining area and have a grayishwhite fresh surface. The main components are quartz, feldspar and black mica. According to ISRM rock mechanics test specifications, cylindrical specimens with a $50 \mathrm{~mm}$ diameter and $100 \mathrm{~mm}$ height were used for the uniaxial compression testing, and those with a $50 \mathrm{~mm}$ diameter and $50 \mathrm{~mm}$ height were used for the Brazilian splitting testing.

The basic physical properties of the rock sample were measured and screened before further testing. The mass testing method used is accurate to $0.01 \mathrm{~g}$, and the volume measurement adopted used a Vernier caliper with an accuracy of $0.1 \mathrm{~mm}$. The average density of the rock sample is $2.63 \mathrm{~g} / \mathrm{cm}^{3}$ after measurement and calculation. The wave velocity of the rock samples was measured by a nonmetallic ultrasonic detector, and a batch of rock samples with a longitudinal wave velocity of $4.8 \pm 0.1 \mathrm{~km} / \mathrm{s}$ were selected.

\section{Test procedure}

1. The granite samples are divided into five groups according to the number of hightemperature water-cooling treatments: 1, 4, 8, 12 and 15 times. There are six granite samples in each group, three of which are for compression tests and three of which are for tension tests, with a total of 30 granite samples, as shown in Fig. 1.

2. The grouped granite samples were put into a SX-12-5.0 box-type resistance muffle furnace for high-temperature heating at $300{ }^{\circ} \mathrm{C}$, with a heating rate of approximately $5{ }^{\circ} \mathrm{C} / \mathrm{min}$ and a holding time of $3 \mathrm{~h}$.

3. After high-temperature heating, the granite samples were clamped with crucible tongs and put into a water tank filled with a large amount of $25{ }^{\circ} \mathrm{C}$ water to cause 


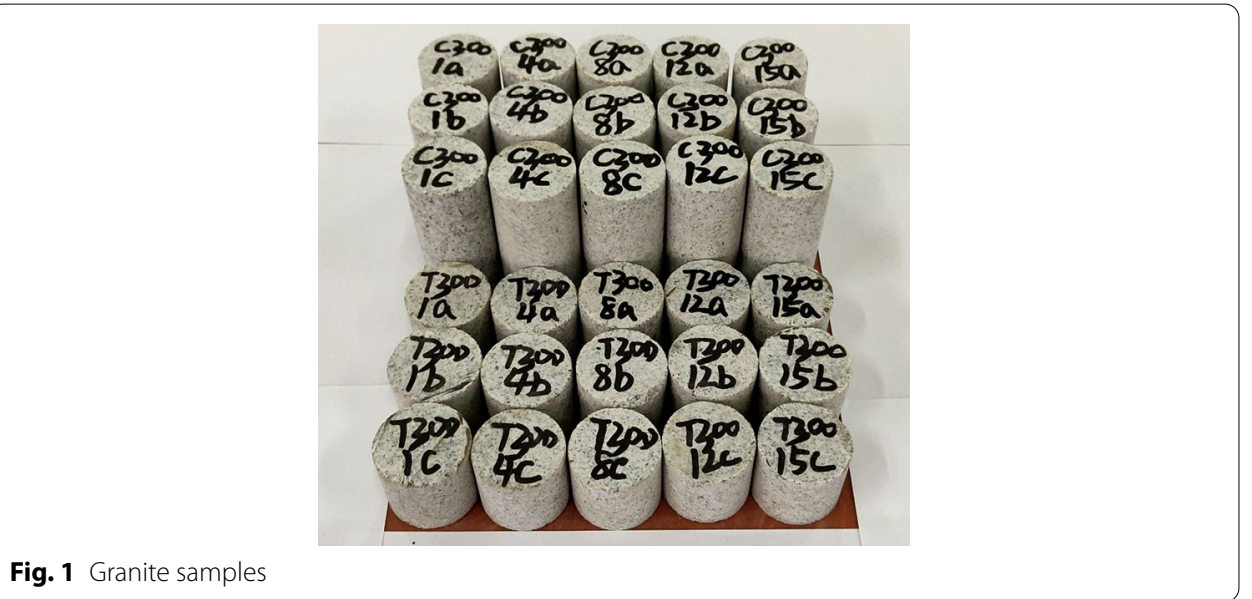

Table 1 Basic physical properties of granite samples under different experimental conditions

\begin{tabular}{llllllllllll}
\hline $\mathrm{N}(\mathrm{C})$ & $\boldsymbol{\varphi}_{\boldsymbol{m}} /(\%)$ & $\boldsymbol{\varphi}_{V} /(\%)$ & $\boldsymbol{\varphi}_{\boldsymbol{\rho}} /(\%)$ & $\omega_{a}(\%)$ & $\boldsymbol{V}_{\mathbf{P}}(\mathrm{km} / \mathbf{s})$ & $\mathrm{N}(\mathrm{T})$ & $\boldsymbol{\varphi}_{\boldsymbol{m}} /(\%)$ & $\boldsymbol{\varphi}_{V} /(\%)$ & $\boldsymbol{\varphi}_{\boldsymbol{\rho}} /(\%)$ & $\omega_{a}(\%)$ & $\boldsymbol{V}_{\mathbf{P}}(\mathrm{km} / \mathbf{s})$ \\
\hline 1 & 0.16 & 0.12 & -0.29 & 0.28 & 3.82 & 1 & 0.15 & 0.21 & -0.36 & 0.47 & 4.2 \\
4 & 0.23 & 0.25 & -0.48 & 0.44 & 3.5 & 4 & 0.16 & 0.39 & -0.55 & 0.53 & 3.92 \\
8 & 0.3 & 0.37 & -0.67 & 0.54 & 3.33 & 8 & 0.2 & 0.6 & -0.79 & 0.58 & 3.81 \\
12 & 0.32 & 0.64 & -0.96 & 0.69 & 3.28 & 12 & 0.2 & 0.81 & -1 & 0.6 & 3.43 \\
15 & 0.32 & 0.82 & -1.13 & 0.74 & 2.99 & 15 & 0.24 & 1.04 & -1.27 & 0.62 & 3.12 \\
\hline
\end{tabular}

$N$ number of thermal shocks, $N$ compressive group, $T$ tensile group

thermal shock and cooling. The cooling time was $6 \mathrm{~h}$, and the samples were weighed after cooling. After the last cycle, the granite was dried in air for more than $48 \mathrm{~h}$ to test its mass, volume and P-wave velocity.

4. According to steps (2) and (3), the cyclic thermal shock treatment of the granite samples in each group was carried out.

5. The static uniaxial compression tests and static Brazilian splitting tests were carried out on the granite samples after the cyclic thermal shock treatment with a WAW3300 universal testing machine. The loading method was displacement control mode, and the loading rate was $0.1 \mathrm{~mm} / \mathrm{min}$. The stress-strain curve and related mechanical parameters of each rock sample were recorded.

\section{Analysis of the test results of the physical properties}

The samples taken in this experiment were all drilled from the same rock, and a batch of rocks with small differences were obtained by wave velocity screening. In order to reduce the uncertainty of the test results, three rocks were taken for parallel tests under each experimental condition. The experimental data with large deviation were removed to obtain the average value of the remaining data in the calculation. Table 1 
shows the average values of the basic physical properties of granite samples under different experimental conditions.

\section{Mass, density and volume}

To investigate the influence of thermal shock cycling on the mass, volume and density of the granite, the mass loss rate, volume expansion rate and density change rate were introduced and calculated by Eqs. (1), (2) and (3) to characterize these changes, as shown in Fig. 2:

$$
\begin{aligned}
& \phi_{m}=\frac{m_{N}-m_{0}}{m_{0}} \times 100 \%, \\
& \phi_{V}=\frac{V_{N}-V_{0}}{V_{0}} \times 100 \%, \\
& \phi_{\rho}=\frac{\rho_{N}-\rho_{0}}{\rho_{0}} \times 100 \%
\end{aligned}
$$

where $\phi_{m}, \phi_{V}$, and $\phi_{\rho}$ are the mass loss rate, volume expansion rate and density change rate, respectively. $m_{N}, V_{N}$, and $\rho_{N}$ are the mass, volume and density, respectively, of a dried granite sample after the last thermal shock treatment. $m_{0}, V_{0}$, and $\rho_{0}$ are the mass, volume and density, respectively, before the thermal shock treatment of the granite.

The mass loss rate of the granite sample remains basically unchanged with an increase in the number of thermal shock cycles. The mass loss is generally most after the first thermal shock cycle, which is caused by the escape of pore water in the granite during the first high-temperature treatment. The volume expansion rate increases monotonically with increasing thermal shock cycles. On the one hand, the high temperature causes the expansion of mineral crystals and thus an increase in volume. On the other hand, due to the different degrees of expansion of different mineral crystals, tensile thermal stress will be generated between the crystals, which will lead to the generation of transgranular cracks. As the number of thermal shock cycles increases, the thermal

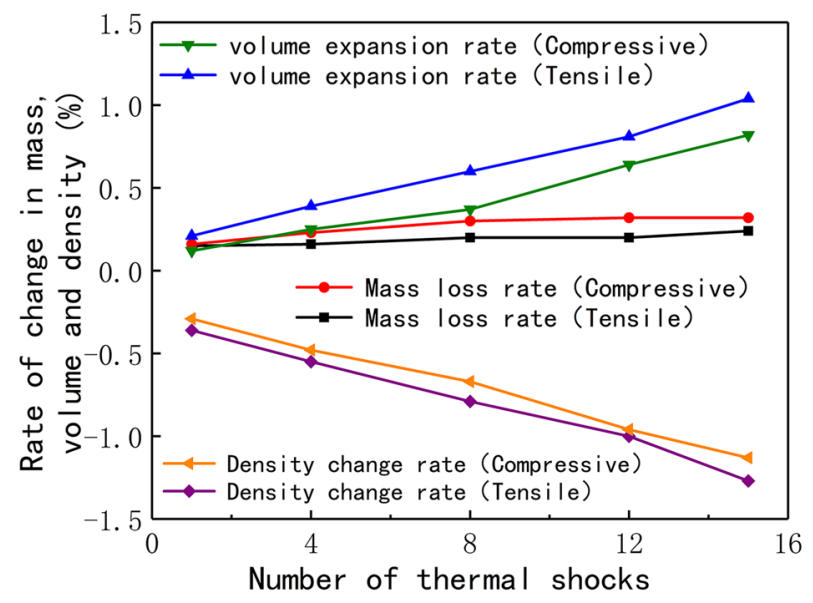

Fig. 2 Changes in mass, volume, and density 
stress increases, and the cracks further develop, which eventually leads to the increase in the volume of the granite. Accordingly, the increase in the number and size of the pores and fractures in the granite will cause the texture of the granite to become looser, its mechanical properties to become weaker, its density to decrease, and its density change rate to be negative.

\section{Water absorption}

To investigate the pores in the rock and the connectivity of the microfissures, the water absorption was calculated by Eq. (4):

$$
\omega_{a}=\frac{m_{w}-m_{N}}{m_{N}} \times 100 \%
$$

where $\omega_{a}$ represents the water absorption and $m_{w}$ represents the mass of the granite after the last cooling treatment. The water absorption of each group after a cooling treatment was calculated, and the results were compared, as shown in Fig. 3. The water absorption of the granite increases with the increase in the number of thermal shocks, and the increase for the tension test group is greater than that for the compression test group. After 15 cycles of thermal shock, the water absorption of the compression test group increased from $0.28 \%$ to $0.74 \%$, and the water absorption of the tension test group increased from $0.47 \%$ to $0.62 \%$. An increase in water absorption indicates an increase in the internal pore size and porosity of the granite, which deteriorates the mechanical properties of the granite.

\section{P-wave velocity}

Ultrasonic testing results can reflect the damage inside the rock. When the inside of the rock is dense, sound waves passing through the rock specimen pass through the medium continuously, resulting in a short acoustic time and fast wave speed. When there are voids and nondense areas inside the rock, the sound waves will rebound when passing by, and the wave path will become longer; thus, the acoustic time through the same length of rock specimen becomes longer and the wave velocity decreases. Figure 4 shows the variation in the P-wave velocity of the experimental granite with increasing number of thermal shocks. The P-wave velocity decreases with an increase in the number of

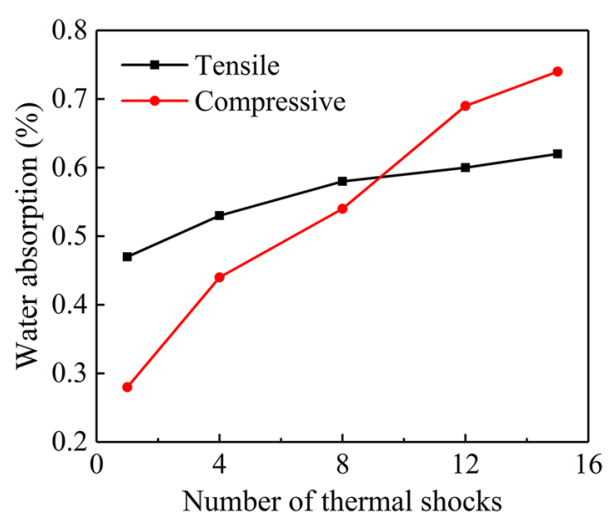

Fig. 3 Changes in water absorption 


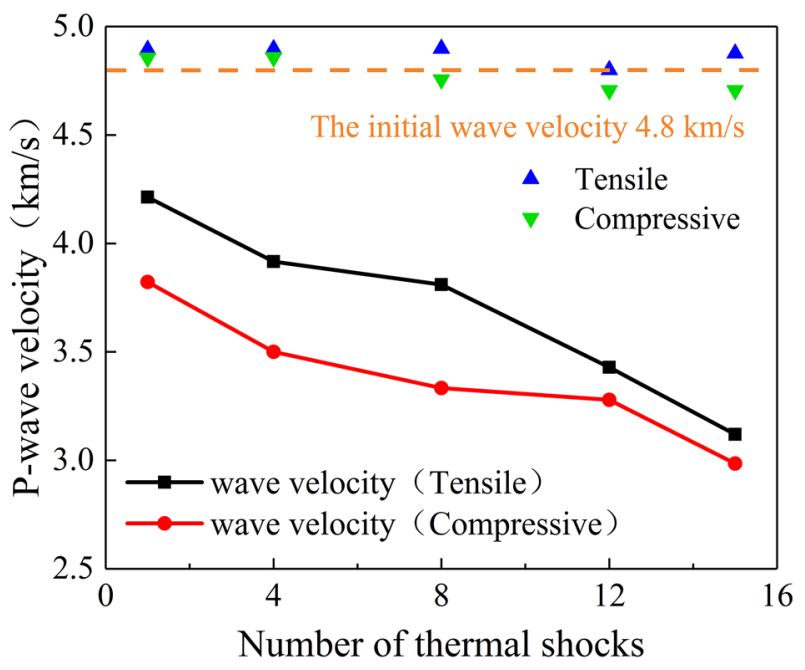

Fig. 4 Changes in P-wave velocity

thermal shocks. The average initial wave velocity of the experimental granite is $4.8 \mathrm{~km} / \mathrm{s}$. After 15 cycles of thermal shock, the wave velocity of the compression test group is reduced to $2.99 \mathrm{~km} / \mathrm{s}$ with a reduction rate of $37.71 \%$, and that in the tension test group is reduced to $3.12 \mathrm{~km} / \mathrm{s}$ with a reduction rate of $35 \%$. The test results show that repeated high-temperature water-cooling and thermal shock treatments will increase the number and size of the voids inside the granite and deteriorate the mechanical properties of the granite.

\section{Microscopic characteristics}

Figure 5 shows the internal SEM (scanning electron microscope) images of the granite after different the number of thermal impacts, with a magnification of 200 times. It can be seen that after the first thermal shock (Fig. $5 \mathrm{a}$ ), the internal structure of the granite is relatively complete without significant change, and the mineral particles are basically cemented together. When the granite sample has undergone 4 thermal shock cycles (Fig. 5b), some microcracks appeared between the minerals. As the number of thermal shocks increases to 15 , the increase in thermal stress causes the microcracks to become wider and longer (Fig. 5c).

\section{Analysis of the test results of the mechanical properties Analysis of the uniaxial compression test results}

\section{Stress-strain relationship}

Table 2 shows the results of the uniaxial compression tests. The selected stress-strain curves of typical granite samples under uniaxial compression for each cycle are compared, as shown in Fig. 6. The variation in a stress-strain curve of granite can be divided into four stages.

1. Compaction stage Due to the existence of pores and voids in the rock, the pores close as the stress increases during the compression process, and the axial strain of the 


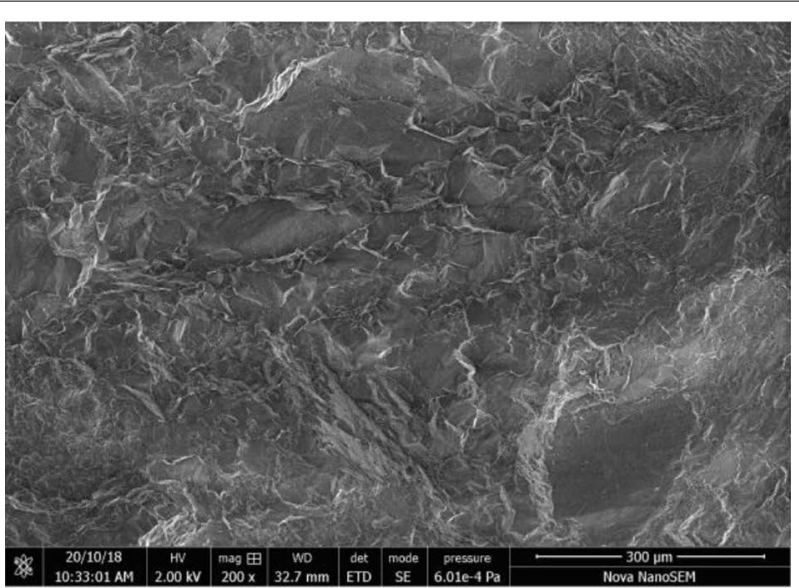

a 1 thermal shock

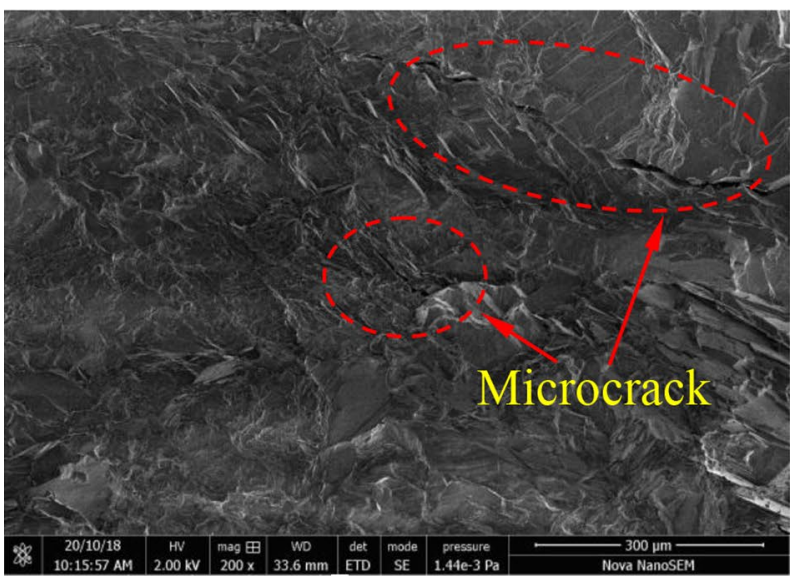

b 8 thermal shocks

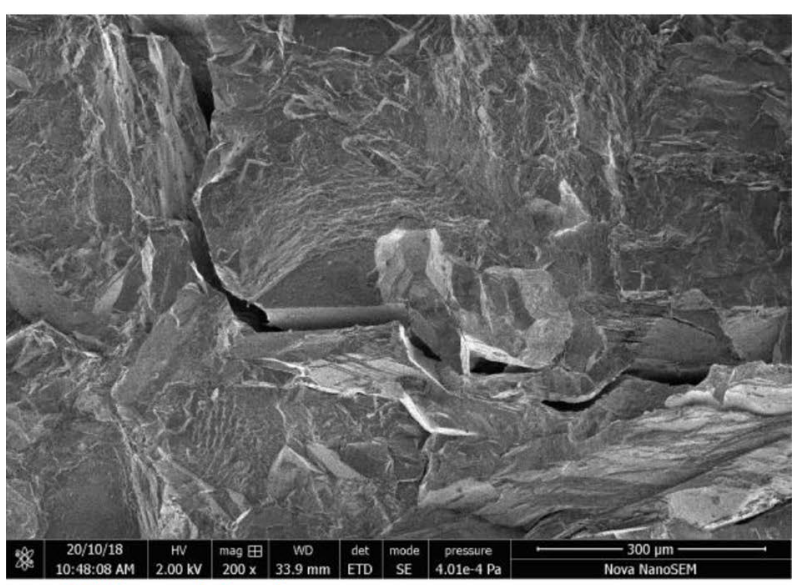

c 15 thermal shocks

Fig. 5 SEM observations of granite under different thermal shocks times

rock increases rapidly; thus, the curve shows a concave shape. Figure 6 shows that as the number of thermal shocks increases, the duration of the compaction stage of the stress-strain curve gradually increases. The increase in the number of thermal 
Table 2 Static uniaxial compression test results

\begin{tabular}{lllll}
\hline Number of thermal shocks & $\mathbf{F} / \mathbf{k N}$ & USC/MPa & $\mathbf{E}_{\mathbf{C}} / \mathbf{G P a}$ & $\mathbf{E}_{\mathbf{5 0}} / \mathbf{G P a}$ \\
\hline 1 & 159.03 & 80.35 & 8.18 & 4.49 \\
4 & 140.85 & 70.6 & 7.58 & 3.79 \\
8 & 122.71 & 65.07 & 8.07 & 3.92 \\
12 & 92.31 & 47.39 & 7.35 & 3.39 \\
15 & 83.78 & 42.67 & 6.19 & 2.91 \\
\hline
\end{tabular}

$F$ maximum test load, USC uniaxial compressive strength, $E_{C}$ elastic modulus, $E_{50}$ deformation modulus

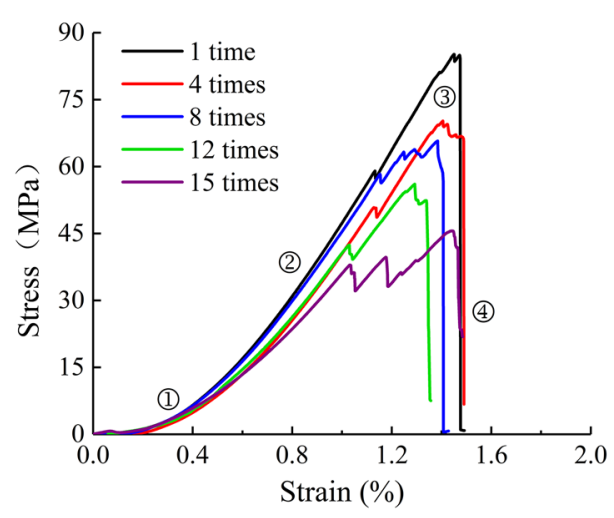

Fig. 6 Stress-strain curves from the uniaxial compression testing

shocks leads to a gradual increase in the size and number of cracks within the granite.

2. Elastic deformation stage After the rock is compacted, the stress continues to increase, and elastic deformation occurs in the rock. The stress and strain at this stage are directly proportional; the curve is linear, and the slope is the elastic modulus. It can be seen in Fig. 6, the duration of the elastic deformation stage gradually decreases with the increase in the number of thermal shocks, which indicates that the bearing capacity of the granite decreases after repeated thermal shocks and the mechanical performance transitions to plasticity.

3. Progressive rupture stage As the stress continues to increase, stable cracking occurs at the surface of the rock sample, and the stress-strain curve drops and rises again. This stage is clearly distinguishable for 8 cycles, after which the granite sample begins to show progressive failure. To better understand the progressive rupture, a scanning electron microscope test was carried out on the granite specimen that was not completely compression failure and the magnification was 2500 times. The result is shown in Fig. 7. It can be seen that there are many closed parallel cracks in the sample, and the crack size is small, between 20 and $100 \mu \mathrm{m}$. The cracks in the figure are dense parallel cracks, which are obviously caused by tensile stress in the same direction. However, the cracks that existed before experimental loading are mostly irregular transgranular and intergranular cracks caused by thermal stress between different crystals. Therefore, it is inferred that these microcracks are caused during the loading test. The microcracks will not cause the instability and failure of the granite imme- 


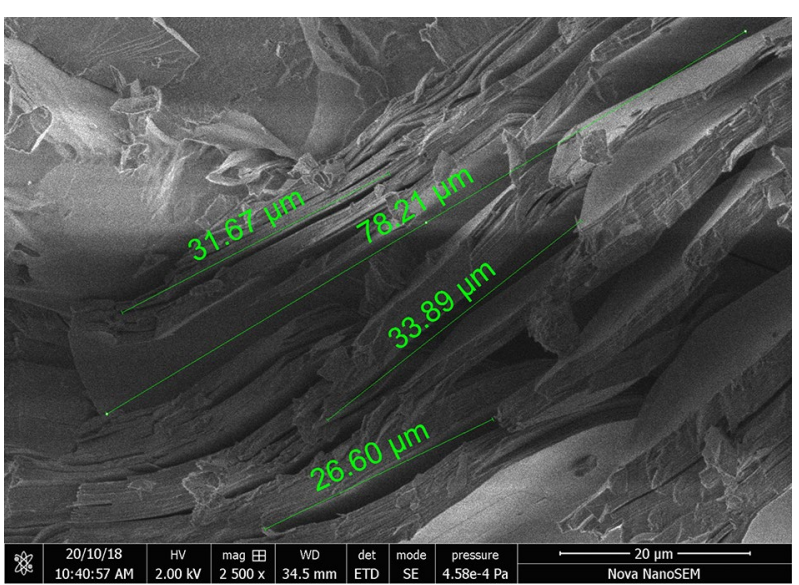

Fig. 7 Microscopic observations of granites during destruction

diately, and with the increase of stress accumulate, which manifests as progressive rupture during the compression process of granite.

4. Failure stage As the stress reaches the peak stress, and the curve drops rapidly. At this point, a large crack forms in the granite sample, running through the entire specimen, which loses its bearing capacity, and a loud noise is emitted. When the number of thermal shocks is one or four, the failure is sudden brittle failure with a loud noise and no visible damage. After four cycles, an obvious cracking phenomenon can be observed before failure. At this time, with the increase in the number of thermal shocks, the failure of the granite sample transitions to progressive plastic failure.

Further analysis of the stress-strain curve form shows that for fewer thermal shocks, that is, one or four, the stress-strain curve presents the characteristics of plastic-elastic changes. The granite sample is destroyed and loses its bearing capacity immediately after the elastic stage. The yield stage of the curve is very short, with an obvious compaction stage and elastic stage. After four cycles, the stressstrain curve transforms and exhibits plastic-elasto-plastic variation characteristics, with an obvious yield stage, the elastic stage is shortened, and the compaction stage increases. On the one hand, the repeated thermal expansion and contraction of the mineral crystals in the granite caused by the high-temperature water-cooling treatment weakens the bond between the crystals. On the other hand, water dissolves some of the cementing material, which also weakens the bond between the crystals and promotes the shedding of mineral particles. All these factors will lead to the degradation of the mechanical properties of the granite, the increase in ductility and plastic deformation during failure. In addition, the generation of thermal stresses after high-temperature water-cooling treatment promotes the development of pores and microfissures within the granite, which is manifested in the growth of the compaction stage of the stress-strain curve. 


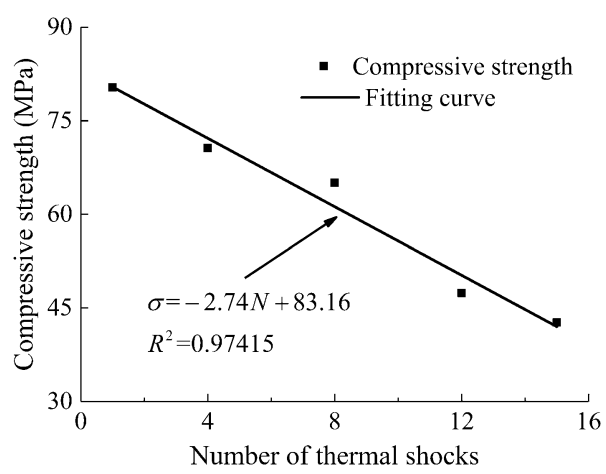

Fig. 8 Compressive strength versus the number of thermal shocks

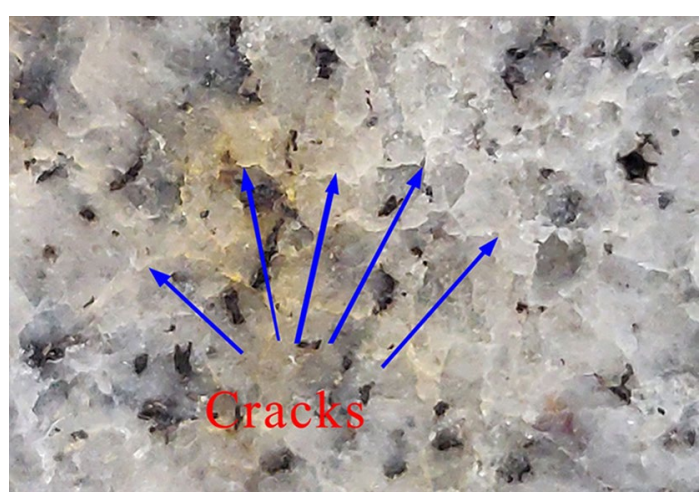

Fig. 9 Transcrystalline cracks at the granite surface

\section{Uniaxial compressive strength}

A static uniaxial compression test of rock can be used to measure the compressive strength of the rock. The test calculation formula is as follows:

$$
\sigma_{c}=\frac{P}{A}
$$

where $\sigma_{c}$ is the unconfined compressive strength of the rock, $\mathrm{MPa} P$ is the maximum test force at rock failure, $\mathrm{kN}$; and $A$ is the cross-sectional area of the sample, $\mathrm{mm}^{2}$.

Figure 8 shows the trend of the unconfined compressive strength of granite with the number of thermal shocks. The compressive strength of granite decreases with an increase in the number of thermal shocks. After 1, 4, 8, 12 and 15 cycles of thermal shocks, the average compressive strengths of the granite samples are $80.35,70.6$, 65.07, 47.39 and $47.39 \mathrm{MPa}$, respectively, a reduction of $46.89 \%$ from $42.67 \mathrm{MPa}$. The linear function was used to fit the change in the average compressive strength with the number of thermal shocks, and the following results were obtained:

$$
\sigma_{c}=-2.74 N+83.16, R^{2}=0.97415 \text {, }
$$

where $N$ is the number of thermal shocks. 
On the one hand, the effect of the high temperature causes the pore water inside the granite to vaporize and escape, and the size and number of the pores and defects increase; on the other hand, when the granite sample undergoes rapid cooling by thermal shock, the internal mineral crystals shrink quickly to different degrees due to their different expansion rates, resulting in tensile stress between the crystals. The tensile stress triggers the generation of transgranular cracks (see Fig. 9). Many transgranular cracks were observed at the surface of the granite sample after thermal shock. Therefore, the effects of high temperature and thermal shock caused great damage to the granite, resulting in significant strength deterioration.

\section{Elastic modulus and deformation modulus}

According to Fig. 10, the elastic modulus and deformation modulus of the granite samples are calculated for different numbers of thermal shocks. The elastic modulus is the slope of the stress-strain curve in the elastic deformation stage, and the deformation modulus is the ratio of half the peak stress to the corresponding strain. Figure 10 shows the relationship between the elastic modulus and deformation modulus and the number of thermal shocks. It can be seen that with the increase in the number of thermal shocks, the elastic modulus basically decreases, with a small increase at 8 thermal shocks. The reason for this trend is presumed to be that the internal crystals of the granite expand due to the high temperature, causing the pores to compact, which results in a large elastic modulus. The final elastic modulus decreased from $8.18 \mathrm{GPa}$ for one thermal shock to $6.12 \mathrm{GPa}$ for 15 thermal shocks, a decrease of $25.18 \%$. With the increase in the number of thermal shocks, the deformation modulus showed the same trend, with the deformation modulus decreasing from 4.49 GPa for one thermal shock to $2.91 \mathrm{GPa}$ for 15 thermal shocks, a decrease of $35.20 \%$.

A polynomial function is used to fit the variations in the elastic modulus and deformation modulus with the number of thermal shocks, and the following fitting curve equations are obtained:

$$
E_{c}=-0.0034 N^{3}+0.067 N^{2}-0.40 N+8.46 R^{2}=0.95984
$$

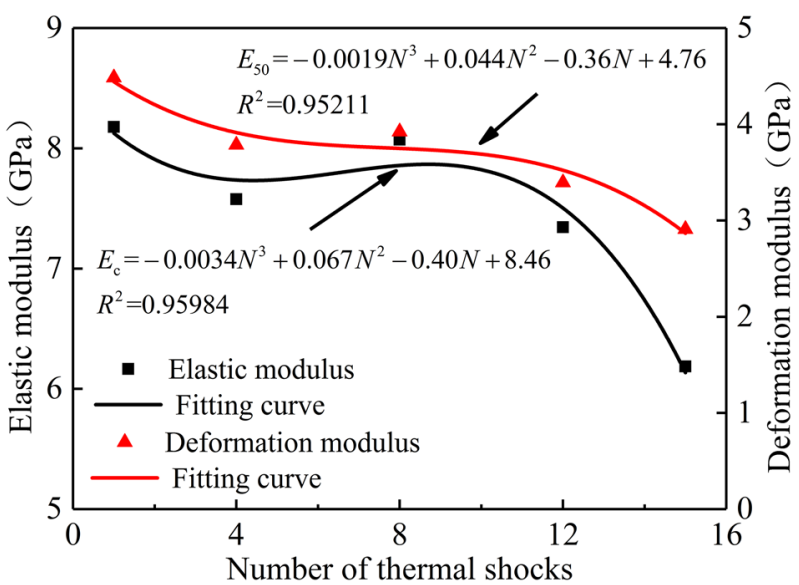

Fig. 10 Elastic modulus and deformation modulus versus the number of thermal shocks 


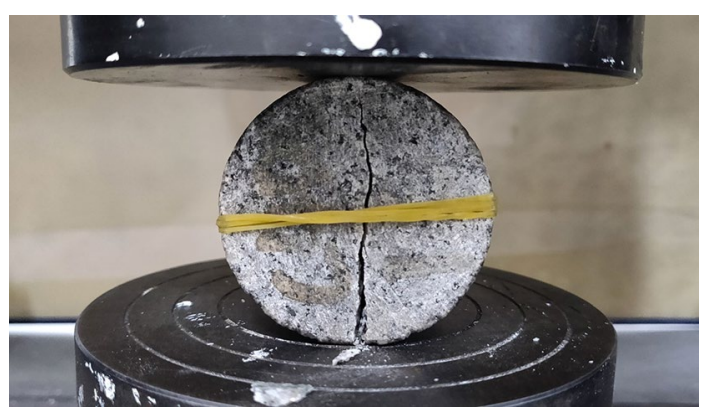

Fig. 11 Photograph of a Brazilian splitting test

Table 3 The results of the static Brazilian splitting tests

\begin{tabular}{llll}
\hline Number of thermal shocks & $\mathbf{P} / \mathbf{k N}$ & $\boldsymbol{\sigma}_{\mathbf{t}} / \mathbf{M P a}$ & $\mathbf{E t} / \mathbf{G P a}$ \\
\hline 1 & 23.68 & 6.03 & 8.20 \\
4 & 21.72 & 5.53 & 7.50 \\
8 & 18.38 & 4.68 & 6.64 \\
12 & 13.67 & 3.48 & 7.10 \\
15 & 12.13 & 3.09 & 4.13 \\
\hline
\end{tabular}

$P$ maximum test load, $\sigma_{t}$ tensile strength, Et tensile modulus

$$
E_{50}=-0.0019 N^{3}+0.044 N^{2}-0.36 N+4.76 R^{2}=0.95211,
$$

where $E_{c}$ is the elastic modulus, GPa; $E_{50}$ is the deformation modulus, GPa; and $N$ is the number of thermal shocks.

The above studies show that repeated high-temperature water-cooling and thermal shock treatments reduce the ability of the granite to resist deformation, which means that the granite will undergo a greater strain at the same stress. This also proves the degradation of granite properties.

\section{Analysis of the Brazilian splitting test results}

To test the tensile strength of granite after different numbers of thermal shocks, the Brazilian splitting test method was used. A concentrated load was applied along the radial direction of the cylindrical specimen, and the specimen cracked in that direction due to the stress, as shown in Fig. 11. Table 3 shows all the results of the Brazilian splitting tests.

\section{Stress-strain relationship}

The stress change of the tensile specimen during the splitting process is calculated according to Eq. (9), and the strain is calculated by the ratio of the displacement in the vertical loading direction to the diameter of the cylindrical specimen. The stress-strain curves of the typical Brazilian splitting test results of a granite sample from each cyclic group are plotted (see Fig. 12). The change in a tensile stress-strain curve of this granite is divided into three stages: compaction stage, elastic deformation stage, and failure stage. With the increase in the number of thermal shocks, the compaction stage increases in duration, the peak of the curve decreases gradually, and the corresponding 


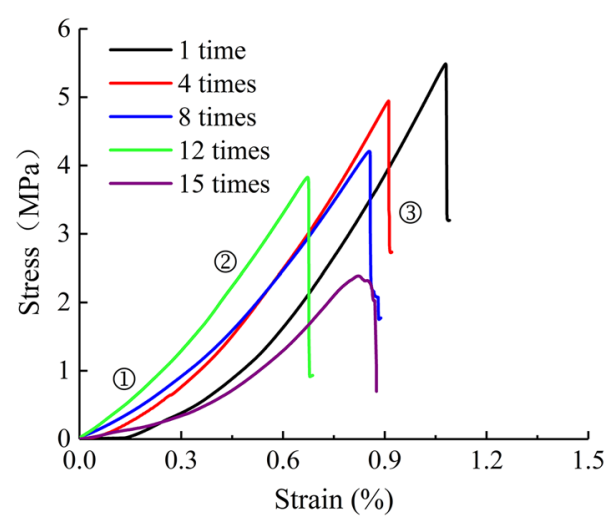

Fig. 12 Stress-strain curves from the Brazilian splitting testing

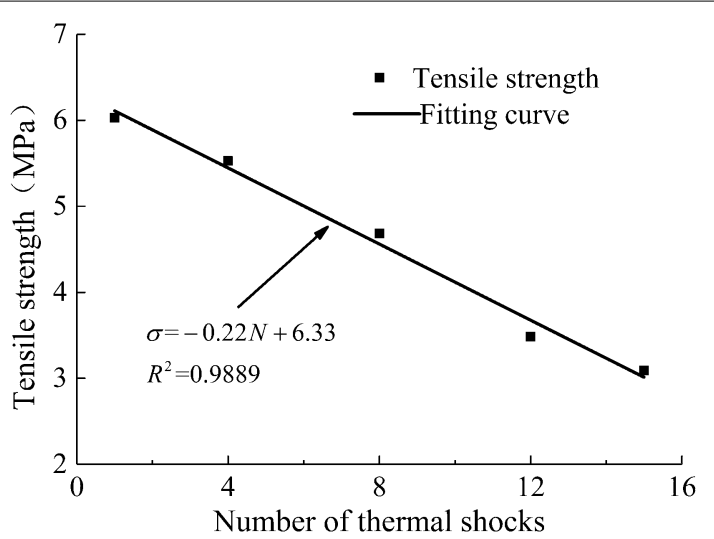

Fig. 13 Tensile strength versus the number of thermal shocks

elastic deformation stage shortens gradually. There is no progressive rupture stage in the Brazilian splitting test curve. The stress drops instantly after reaching the peak, resulting in a linear part of the curve, which is caused by the instantaneous fracturing of the rock sample in the middle of the sample.

\section{Tensile strength}

According to the elastic mechanics formula, the cylindrical specimen will exhibit an approximately uniform tensile stress in the horizontal radial direction under vertical radial loading, and the average tensile stress is the tensile strength of the rock. The tensile strength of the rock specimen can be calculated by the following formula:

$$
\sigma_{t}=\frac{2 P}{\pi D l},
$$

where $\sigma_{t}$ is the tensile strength of the rock, MPa; $\mathrm{P}$ is the maximum test force at rock failure, $\mathrm{kN}$; $D$ is the diameter of the cylindrical sample, $\mathrm{mm}$; and $\mathrm{L}$ is the height of the cylindrical sample, $\mathrm{mm}$.

Figure 13 is a plot showing the trend of the tensile strength of the granite with increasing number of thermal shocks, and it can be seen that the tensile strength of the 
granite decreases with the increase in the number of thermal shocks. The tensile strength decreases from 6.03 MPa after one thermal shock to $3.09 \mathrm{MPa}$ after 15 thermal shocks, with a decrease of $46.76 \%$. This indicates that cyclic thermal shocks weaken the tensile strength of the granite, and the change in the average tensile strength with the number of thermal shocks is fitted by a linear function. The following results are obtained:

$$
\sigma_{t}=-0.22 N+6.33, R^{2}=0.9889,
$$

where $N$ is the number of thermal shocks.

\section{Tensile modulus}

The slope of the elastic phase of the stress-strain curve during the Brazilian splitting test of the sample is regarded as the tensile elastic modulus, which can reflect the tensile deformation ability of granite. That is, the smaller the tensile modulus, the greater the deformation produced by the specimen under the same stress increment. The tensile modulus of a granite sample under different numbers of thermal shocks is calculated according to Fig. 12. Figure 14 shows the relationship between the tensile modulus and the number of thermal shocks. It can be seen that with the increase in the number of thermal shocks, the tensile modulus basically decreases. A small increase of $7 \%$ at 12 thermal shock cycles, but it did not affect the overall downward trend, from 8.20 GPa after one thermal shock to $4.13 \mathrm{GPa}$ after 15 thermal shocks, a decrease of $49.63 \%$.

\section{Discussion}

\section{Correlation analysis of the physical and mechanical properties}

The above analysis found that the physical and mechanical properties of granite degrade with an increasing number of thermal shocks. The fundamental reason for the decrease in the strength of the granite is the increase in the size and number of the internal pores and microfissures and the weakening of the bond between the mineral crystals. The decrease in P-wave velocity is also caused by the increase in the size and number of the pores and microfissures in the granite. Here, the water absorption is used to reflect the porosity of the rock. Therefore, the relationship between the water absorption, P-wave velocity, compressive strength, tensile strength of the granite are analyzed. Figure 15 shows the fitting

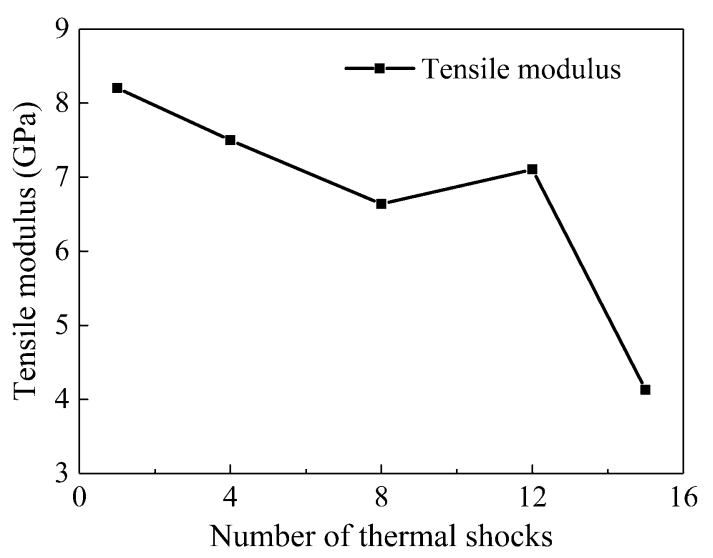

Fig. 14 Tensile modulus versus the number of thermal shocks 


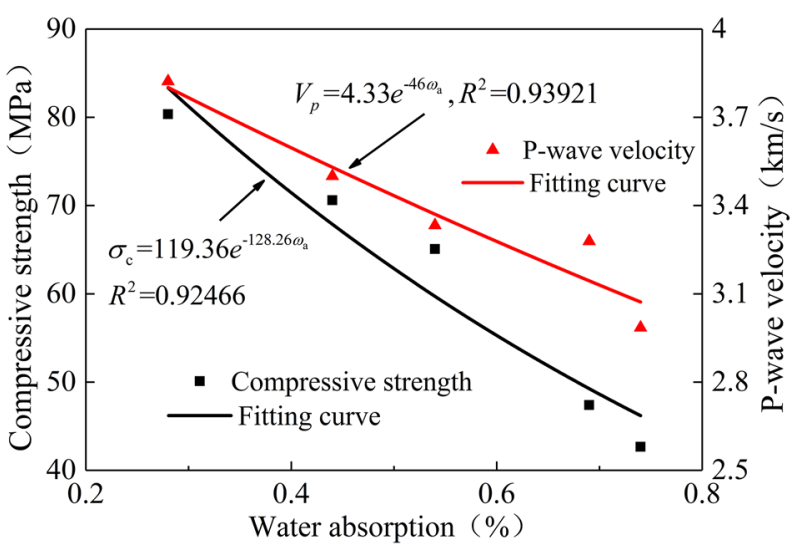

Fig. 15 Compressive strength and P-wave velocity versus water absorption

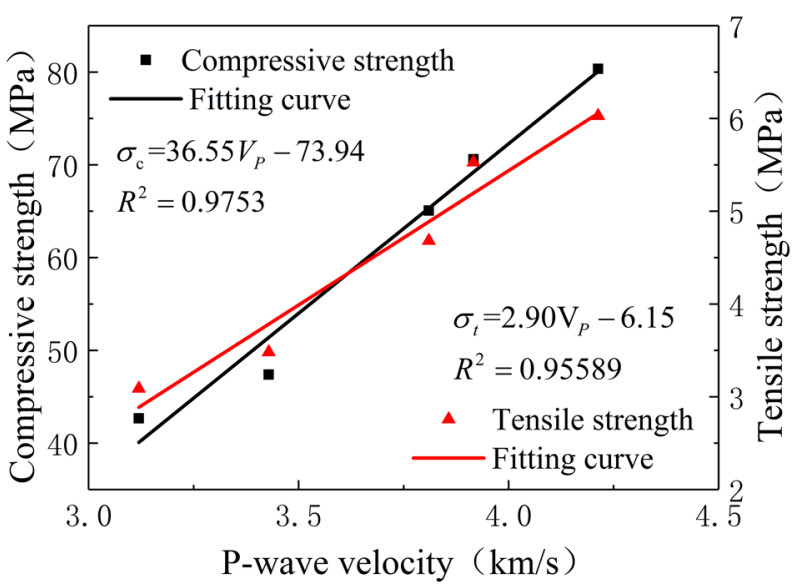

Fig. 16 Compressive strength and tensile strength versus P-wave velocity

relationship diagram between the water absorption and the compressive strength and the water absorption and the P-wave velocity. The compressive strength and longitudinal wave velocity both decrease with increasing water absorption, and the fitting formulas are as follows:

$$
\begin{aligned}
& \sigma_{c}=119.36 e^{-128.26 \omega_{a}}, R^{2}=0.92466 \\
& V_{p}=4.33 e^{-46 \omega_{a}}, R^{2}=0.93921
\end{aligned}
$$

where $V_{p}$ is the P-wave velocity of the granite.

Figure 16 shows the fitting relationship diagram between the compressive strength, the tensile strength, and the longitudinal wave velocity. It can be seen that the compressive strength and tensile strength of granite are linearly correlated with the longitudinal wave velocity. The fitting formulas are as follows:

$$
\sigma_{c}=36.55 V_{P}-73.94, R^{2}=0.9753 \text {, }
$$


$\sigma_{t}=2.90 V_{P}-6.15, R^{2}=0.95589$

The fitting result is good.

\section{Mechanical correlation analysis}

According to the above studies, it can be seen that the tensile strength of this granite is much lower than its compressive strength, and both decrease with the increase in the number of thermal shocks. The relationship between the compressive strength and tensile strength of the granite after thermal shock is analyzed by fitting. Figure 17 shows the fitting curve, and the fitting formula is as follows:

$$
\sigma_{c}=12.41 \sigma_{t}+4.62, R^{2}=0.98866
$$

The fitting result of Eq. (15) is good, and it is found that the compressive strength and tensile strength of the granite after different numbers of thermal shocks have a linear relationship.

\section{Calculation of the $\mathrm{m}$ and $\mathrm{s}$ values of damaged granite based on the Hoek-Brown empirical criterion}

Hoek and Brown carried out many indoor experiments and tests on rocks, analyzed the results, and proposed empirical criteria for rock strength, which are widely used in rock engineering. The Hoek-Brown empirical criteria are as follows:

$$
\frac{\sigma_{1}}{R_{C}}=\frac{\sigma_{3}}{R_{C}}+\left(m \frac{\sigma_{3}}{R_{C}}+s\right)^{\frac{1}{2}}
$$

where $R_{C}$ represents the uniaxial compressive strength of the intact rock, $m$ and $s$ are constants, depending on the nature of the rock and the degree of disturbance or damage to the rock before being subjected to failure stresses $\sigma_{1}$ and $\sigma_{3}$.

If $\sigma_{3}=0$ in Eq. (16), the uniaxial compressive strength of the rock can be obtained:

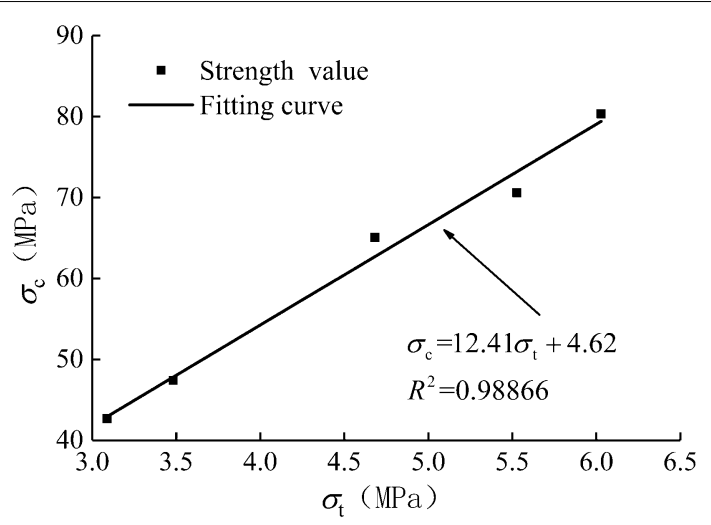

Fig. 17 The relationship between compressive strength and tensile strength 


$$
R_{C m}=R_{C} \sqrt{s}
$$

If $\sigma_{1}=0$ in Eq. (16), the tensile strength of the rock can be obtained:

$$
R_{t m}=\frac{1}{2} R_{C}\left[m-\sqrt{m^{2}+4 s}\right] .
$$

In this test, the intact rock without any treatment is subjected to a uniaxial compression test, and $R_{C}=90.06 \mathrm{MPa}$ is obtained.

The following can be deduced:

$$
\begin{aligned}
& s=\left(\frac{R_{C m}}{R_{C}}\right)^{2}, \\
& m=\frac{R_{t m}}{R_{C}}-\frac{R_{C} s}{R_{t m}},
\end{aligned}
$$

where $R_{C m}$ represents the measured value of the uniaxial compressive strength and $R_{t m}$ represents the measured value of the tensile strength.

Therefore, the $m$ and $s$ values of the damaged granite after multiple thermal shock effects can be calculated based on the strength values obtained from the test (see Table 4). As the number of thermal shocks increases, both the $m$ and $s$ values decrease, indicating that the thermal shock has caused damage to the granite. The $m$ and $s$ results can be used to judge the quality and mechanical properties of engineering rock masses and can also provide a reference for the failure of engineering rock masses subjected to thermal shock.

\section{Conclusion}

1. After several high-temperature $\left(300{ }^{\circ} \mathrm{C}\right)$ water-cooling and thermal shock treatments, the pores and fissures of granite develop continuously, which causes the volume of the granite to expand, the density to decrease, the water absorption to increase, and the P-wave velocity to decrease.

2. The uniaxial compressive stress-strain curve of the granite transitions from a plasticelastic form to a plastic-elastic-plastic form after multiple thermal shocks. The compaction stage and progressive rupture stage gradually increase in duration, and the elastic deformation stage is shortened. The stress-strain curve of a Brazilian splitting test is basically divided into three stages, namely, the compaction stage, elastic deformation stage and postpeak stage.

Table 4 The $m$ and $s$ values of granite based on the Hoek-Brown empirical criterion

\begin{tabular}{llllll}
\hline $\begin{array}{l}\text { Number of thermal } \\
\text { shocks }\end{array}$ & $\mathbf{1}$ & $\mathbf{4}$ & $\mathbf{8}$ & $\mathbf{1 2}$ & $\mathbf{1 5}$ \\
\hline$m$ & 11.83 & 9.95 & 9.99 & 7.12 & 6.51 \\
$s$ & 0.78 & 0.61 & 0.52 & 0.28 & 0.22 \\
\hline
\end{tabular}


3. As the number of thermal shocks increases, the compressive strength and tensile strength of the granite decrease, showing a linear decline. The compressive modulus and tensile modulus also decrease, dropping by $35.20 \%$ and $46.76 \%$, respectively, after 15 thermal shock cycles. This indicates that the thermal shock effect reduces the bearing capacity of the rock and thus its ability to resist deformation.

4. The P-wave velocity, compressive strength and water absorption of granite are negatively correlated. There is a linear relationship between the tensile strength and compressive strength.

5. Based on the Hoek-Brown empirical criterion, the $m$ and $s$ values of damaged granite were calculated. The $m$ value of the granite is between 2.5 and 12.5, and the $s$ value is between 0.1 and 1 . Both decrease with the increase in the number of thermal shocks. The decrease in the $m$ and $s$ values also indicates that the damage degree of granite increases.

6. After a number of high-temperature water-cooling and thermal shock treatment cycles, due to the different degrees of expansion and contraction between the mineral crystals, large thermal stresses are generated between the crystals, resulting in the formation of transcrystalline cracks on the granite surface. It can be seen from the SEM images that with the increase of the number of thermal shocks, the microcracks in the granite gradually formed and widened. Combined with the deterioration of its physical and mechanical properties, it can be seen that the granite is greatly damaged by thermal shock.

\section{Acknowledgements}

Thanks to the laboratory staff of Hebei University. Support was provided by College of Civil Engineering and Architecture, HeBei University, Baoding 071002. Funding was provided by the Hebei Province Education Department Fund (BJ2018046) and Graduate innovation and entrepreneurship project of Hebei University (hbu2020ss027).

\section{Authors' contributions}

YL designed the study and performed the experiments; PHW, ZY and LGW performed the experiments; PHW analyzed the data, and wrote the manuscript. All authors read and approved the final manuscript.

Funding

Hebei Province Education Department Fund (BJ2018046). Graduate innovation and entrepreneurship project of Hebei University (hbu2020ss027).

Availability of data and materials

The data and materials are authentic and reliable.

Competing interests

There is no dispute of interest with others.

Received: 22 September 2020 Accepted: 20 January 2021

Published online: 26 January 2021

\section{References}

Chen Z, Xu G, Jiang M. Current situation and development suggestions of hot dry rock fracturing technology at home and abroad. Pet Drill Technol. 2019;47:1-8. https://doi.org/10.11911/syztjs.2019110.

Dai J, Wang S, Wang C. Experimental research on the effect of different cooling methods on the strength of granite after microwave irradiation. Sci Technol Eng. 2018;18:170-4.

Faoro I, Vinciguerra S, Marone C, Elsworth D, Schubnel A. Linking permeability to crack density evolution in thermally stressed rocks under cyclic loading. Geophys Res Lett. 2013;40(11):2590-5.

Jin P, Hu Y, Shao J, Zhao G, Zhu X, Li C. Influence of different thermal cycling treatments on the physical, mechanical and transport properties of granite. Geothermics. 2019;78:118-28. https://doi.org/10.1016/j.geothermics.2018.12.008.

Li E, Wang Y, Chen L, Liu Y, Tan Y, Duan J, Pu S, Wang J. Experimental study on thermal damage mechanical properties of beishan granite. J China Univ Min Technol. 2018;47:735-741 779. https://doi.org/10.13247/j.cnki.jcumt.000881. 
Li B, Ju F, Xiao M, Ning P. Mechanical stability of granite as thermal energy storage material: an experimental investigation. Eng Fract Mech. 2019;211:61-9. https://doi.org/10.1016/j.engfracmech.2019.02.008.

Luo S, Dou B, Tian H, Chen J, Xiao P, Zhang S. Comparative experimental study on physical and mechanical properties of granite after natural cooling and real-time high temperature. Earth Sci Front. 2020;27:178-84. https://doi. org/10.13745/j.esf.2020.1.19.

Que B, Wu Y, Zhao Y. Experimental study on correlation between macroscopic mechanical parameters and thermal shock velocity of granite under thermal shock. Chin J Rock Mech Eng. 2019;47:1-8. https://doi.org/10.13722/j.cnki. jrme.2019.0230.

Que B, Wu Y, Wang S, Xiong G, Zhao Y. Experimental study on high temperature thermal damage mechanical properties of granites in Gonghe Basin, Qinghai. Chin J Rock Mech Eng. 2020;39:69-83. https://doi.org/10.13722/j.cnki. jrme.2019.0182.

Rao MVMS, Ramana YV. A study of progressive failure of rock under cyclic loading by ultrasonic and AE monitoring techniques[J]. Rock Mech Rock Eng. 1992;25(4):237-51.

Shu RH, Yin TB, Li XB, Yin ZQ, Tang LZ. Effect of thermal treatment on energy dissipation of granite under cyclic impact loading[J]. Trans Nonferrous Metals Soc China. 2019;29(2):385-96. https://doi.org/10.1016/S1003-6326(19)64948-4.

Wang T, Guo J, Zhan Q, Shuai H, Song Y. Research on threshold calculation method of rock thermal fracture. Chin J Undergr Space Eng. 2019a;15:86-91.

Wang JT, Zuo JP, Sun YJ, Wen JH. The effects of thermal treatments on the fatigue crack growth of Beishan granite: an in situ observation study[J]. Bullet Eng Geol Environ. 2019b. https://doi.org/10.1016/S1003-6326(19)64948-4.

Xu C, Sun Q, Pan X, Zhang W, Wang Y. Variation on thermal damage rate of granite specimen with thermal cycle treatment. High Temp Mater Process. 2019;38:849-55. https://doi.org/10.1515/htmp-2019-0046.

Yang J, Zhang G, Qiao T. Mechanical damage model and verification of rock under thermal-hydraulic coupling. China Saf Sci Technol. 2017;13:87-93. https://doi.org/10.11731/j.issn.1673-193x.2017.04.015.

Yu L, Yan M, Chen Y, et al. Experimental study on uniaxial mechanical properties of granite under thermo-hydraulic coupling. Sci Technol Eng. 2019;19:311-8.

Yu L, Yan M, Chen Y, Peng H. Experimental study on uniaxial mechanical properties of granite under thermo-liquid coupling. Indian Geotech J. 2020. https://doi.org/10.1007/s40098-020-00428-0.

Zhang S, Zhang L, Tian C, Cai J, Tang B. Geological characteristics and development potential of hot dry rocks in Gonghe Basin, Qinghai. Chin J Geomech. 2019a;25:501-8. https://doi.org/10.12090/j.issn.1006-6616.2019.25.04.048.

Zhang Y, Zhang X, Liang P, Chen S, Sun L, Yao X, Liu X, Liang J. Experimental study on the time-frequency characteristics of acoustic emission transverse and longitudinal waves during granite fracture. Chin J Rock Mech Eng. 2019b;38:3554-64. https://doi.org/10.13722/j.cnki.jrme.2019.0250.

Zhao GK, Hu YQ, Jin PH. Exploratory experimental study on the mechanical properties of granite subjected to cyclic temperature and uniaxial Stress [J]. Energies. 2020. https://doi.org/10.3390/en13082061.

\section{Publisher's Note}

Springer Nature remains neutral with regard to jurisdictional claims in published maps and institutional affiliations.

\section{Submit your manuscript to a SpringerOpen ${ }^{\circ}$ journal and benefit from:}

- Convenient online submission

- Rigorous peer review

- Open access: articles freely available online

- High visibility within the field

- Retaining the copyright to your article

Submit your next manuscript at $\boldsymbol{\Delta}$ springeropen.com 